\title{
Current Insights into Treating Vertigo in Older Adults
}

\author{
Augusto Pietro Casani ${ }^{1}\left[\right.$ ] $\cdot$ Mauro Gufoni $^{1}$ (D) $\cdot$ Silvia Capobianco ${ }^{1}$ (i)
}

Accepted: 5 June 2021 / Published online: 23 June 2021

(c) The Author(s) 2021

\begin{abstract}
The number of older people has been increasing over recent decades in Western populations. Dizziness, imbalance, and vertigo constitute some of the most common complaints in older patients, and risk of falling is the most frequent and worrying consequence. It has been reported that $15-20 \%$ of the adult population experiences these debilitating symptoms. Among the diseases that may be associated with vertigo, the three classes of otological, central, and functional (psychological) dizziness may be distinguished. Overall, vestibular disorders account for $48 \%$ of vertiginous complaints in the older population. The main focus of this article is to review the forms of pharmacotherapy for vertigo, especially with regard to older patients, who may be treated simultaneously with other drugs for different comorbidities. Interactions with other drugs should be considered in the choice of a particular course of treatment. Moreover, overuse of pharmacotherapy for the management of vertigo in the elderly may prevent the development of the central compensatory mechanism that sustains both static and dynamic imbalance after a vertiginous crisis. In the majority of patients, vestibular and physical rehabilitation are strongly advised and rarely contraindicated.
\end{abstract}

\section{Introduction}

Vertigo and dizziness affect $15-20 \%$ of the adult population [1] and contribute to falls, especially in older patients, among whom $23 \%$ are subjected to fall-associated trauma at least once a year [2, 3]. Hearing loss has also been recognized as a predisposing factor to accidental falls [4].

Normal balance is the result of the interaction between the inputs derived by the peripheral vestibular system (semicircular canals and otolith organs), which are integrated in the vestibular nuclei with proprioceptive and visual information. As a result of the integration of these three different perceptive inputs, the central nervous system (CNS) generates a series of reflexes that guarantee proper balance. A wide range of neurotransmitters underlie this highly complex neural activity, among which glutamate, acetylcholine, and glycine play a relevant role and are further modulated by histamine, adrenaline, and noradrenaline [5].

Augusto Pietro Casani

augusto.casani@unipi.it

1 Department of Surgical Pathology, Medical, Molecular and Critical Area, ENT Section, Pisa University Hospital, Via Paradisa, 2, 56126 Pisa, Italy

\section{Key Points}

Vertigo and dizziness frequently affect the adult population and greatly contribute to fall-associated trauma, especially in older patients; the three classes of otological, central, and functional dizziness may be distinguished.

Older patients are subjected to multiple comorbidities and various pharmacological therapies, which in turn could cause dizziness.

The use of vestibular suppressants for the management of vertigo should be limited only to the acute phase of the disease, and such drugs must be used with caution in the older population because of their side effects and potential interactions with other pharmacological treatments.

In older patients, physical activity and vestibular rehabilitation exercises are recommended for more rapid and complete vestibular compensation; repositioning maneuvers are highly indicated and effective in the older population with benign paroxysmal positional vertigo. 
The aim of this work is to review the prescriptions and especially contraindications of drugs currently used in clinical practice in older patients with stability issues.

Conventionally, disorders that cause vertigo (the sensation of self-motion when no self-motion is occurring) or dizziness (the sensation of disturbed or impaired spatial orientation without a false or distorted sense of motion) [6] have been classified into three broad categories:

1. Otological vertigo or dizziness

2. Central vertigo or dizziness

3. Psychogenic (functional) dizziness [7]

The terms 'dizziness' and 'vertigo' are commonly used to indicate a variety of symptoms regarding disorders of spatial orientation and motion perception; older patients tend to report less rotatory vertigo and more non-specific dizziness and unsteadiness than younger patients presenting with the same conditions $[8,9]$; for this reason, a detailed patient history is key for diagnosis.

Peripheral vestibular disorders are the most common and may be treated both pharmacologically and through vestibular rehabilitation. Even when an effective treatment is not possible, a compensatory mechanism may develop in the CNS and improve the patient's ability to maintain both static and dynamic balance [10]. The importance of the vestibular compensation must be taken into consideration when prescribing pharmacotherapy, as some drugs applied in the treatment of vertigo may negatively impact the development of the compensatory phenomenon, and therefore their usage must be limited to brief periods of time, especially in older patients, in whom numerous comorbidities (impaired musculoskeletal functions, inadequate CNS activity, impaired visual input) could negatively affect this mechanism.

Central vestibular disorders are less frequent than peripheral conditions, but must be considered given their impact on both the prognosis and the rehabilitation.

Psychogenic dizziness could be the consequence of some psychiatric disorders (anxiety, depression, obsessive disorders), but at the same time, a vestibular disease (especially when unrecognized) could be negatively affected by a concomitant psychiatric illness. In these cases, pharmacological, psychotherapeutic, and rehabilitative treatments could provide satisfactory results.

Finally, it is not uncommon that a conclusive diagnosis for a balance disorder cannot be found, despite the wide variety of otoneurological clinical and instrumental tests available. In these cases, symptomatic treatment could be undertaken, but it must be considered that older patients are often treated for multiple comorbidities with numerous drugs, among which some may constitute the main cause of dizziness in the first place.

For this reason, a fundamental step when approaching an older patient suffering from vertigo is constituted by a review of the patient's medication history. Firstly, some drugs (e.g., acetyl-salicylic acid, amiodarone, cisplatin, quinine, furosemide, gentamicin, and streptomycin) could directly damage the inner ear cochlear and vestibular receptors, resulting in permanent ataxia or hearing loss. Many other drugs belonging to different categories could cause dizziness or disequilibrium [11] (Table 1). Furthermore, it must be noted that orthostatic hypotension, which may manifest as dizziness, is highly prevalent in the older population. The occurrence of orthostatic hypotension in older patients likely reflects multiple disease processes, including neurological and cardiovascular conditions, as well as the effect of several medications, such as diuretics, alpha-adrenoceptor blockers for prostatic hypertrophy, antihypertensive drugs, and calcium channel blockers. In the case of drug-induced dizziness and vertigo, symptoms usually resolve after the cessation of the causal drug [12].

Figure 1 shows the differential prevalence of the various forms of vestibular diagnosis in young and older dizzy patients referred to our tertiary referral center in the time period from January 2016 to December 2019.

In addition to a well-defined cause of vertigo in older patients, the physiological deterioration of the vestibular system associated with other functional disorders of aging (presbyopia, cataract, sarcopenia, etc.) could lead to a condition of chronic dizziness, postural imbalance, and gait disturbance and to an increased risk for recurrent falls. This condition is named presbyvestibulopathy, and recently, strict diagnostic criteria have been published [13] with the aim of ensuring a suitable categorization and homogenization of these patients. At this time, no pharmacological treatment for presbyvestibulopathy is indicated, and a strong body of evidence supports the usefulness of vestibular rehabilitation [14].

The main focus of this review is the forms of vertigo that can be treated pharmacologically. 
Table 1 Drugs that may induce dizziness

\begin{tabular}{ll}
\hline Class & Examples of drugs \\
\hline Anti-inflammatories & NSAIDs: ibuprofen, celecoxib, diclofenac, dexketoprofen, ketorolac, naproxen, indomethacin \\
& Salicylates: acetylsalicylic acid \\
& Analgesics: acetaminophen \\
& SSRIs: all \\
& TCAs: amitriptyline, imipramine, nortriptyline, trazodone \\
MAOIs: phenelzine, selegiline & Others: bupropion, mirtazapine, nefazodone, venlafaxine \\
& Alpha-blockers: prazosin, terazosin \\
& Beta-Blockers: atenolol, propranolol \\
Calcium channel blockers: nifedipine, verapamil, amlodipine, lacidipine, nicardipine & ACE inhibitors: enalapril, zofenopril \\
Antihypertensives & Angiotensin II receptor blockers: irbesartan \\
& Barbiturates, phenytoin, ethosuximide \\
Anticonvulsants & Chlorpromazine, fluphenazine, perphenazine, prochlorperazine, thioridazine, trifluoroperazine, clozapine \\
Antipsychotics & Bromocriptine, levodopa/carbidopa \\
Anti-parkinsonian drugs & Cyclobenzaprine, orphenadrine \\
Muscle relaxants & Alprazolam, chlordiazepoxide, clonazepam, diazepam, lorazepam, oxazepam \\
Anxiolytics & Carbamazepine, gabapentin, lamotrigine, oxcarbazepine \\
Mood stabilizers &
\end{tabular}

Modified from Chimirri et al. [11]

$A C E$ angiotensin-converting enzyme, MAOI monoamine oxidase inhibitor, NSAID non-steroidal anti-inflammatory drug, SSRI selective serotonin reuptake inhibitor, $T C A$ tricyclic antidepressant

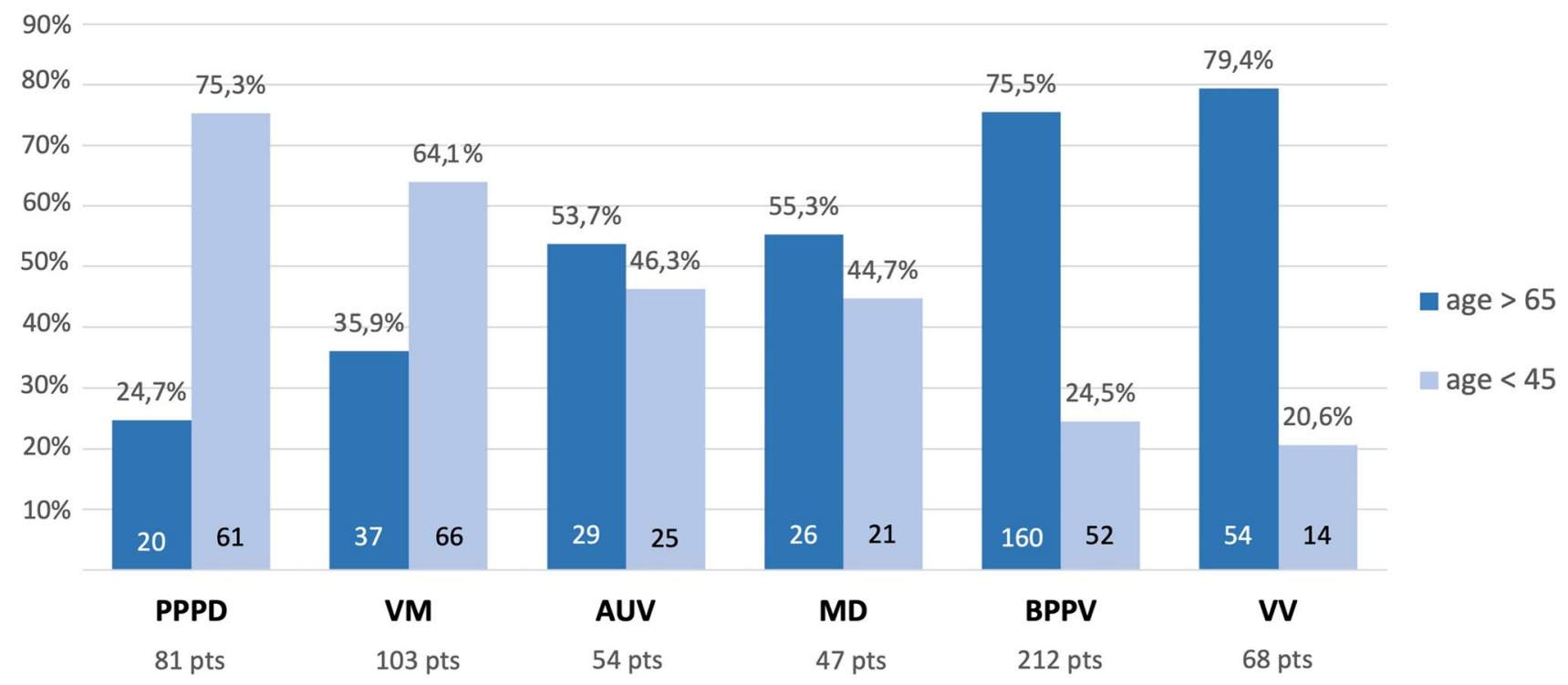

Fig. 1 Distribution of the most frequent vestibular diagnoses relative to age $(<45$ and $>65)$ in 565 patients referred to the Center of Balance Disorders of the Ear Nose and Throat Department, Pisa University Hospital (January 2016-December 2019). AUV acute unilateral

vestibulopathy, $B P P V$ benign paroxysmal positional vertigo, $M D$ Menière's disease, $P P P D$ persistent postural-perceptual dizziness, $p t s$ patients, $V M$ vestibular migraine, $V V$ vascular vertigo 


\subsection{Search Methods}

A narrative review of the literature with holistic interpretation based on the authors' own experience was chosen as the most appropriate technique for our study because of the comprehensive nature of the topic. For this reason, we did not conduct a systematic literature search and we did not perform a quality assessment. However, a search of the PubMed database (up to February 2021) was conducted for relevant publications using combinations of the following terms: "drugs," "pharmacological treatment," "vertigo," "vestibular migraine," "benign positional vertigo," "acute vertigo," "persistent postural perceptual dizziness," and "vascular vertigo." The results were evaluated according to the pertinence to the review topic.

\section{Peripheral Vertigo and Dizziness}

\subsection{Acute Unilateral Vestibulopathy (AUV)}

Acute unilateral vestibulopathy (AUV) is a clinical condition characterized by a sudden onset of vertigo, nausea, vomiting, gait instability, and falling tendency towards the affected side without associated cochlear or CNS signs and symptoms [15]. AUV is due to a lesion of the vestibular nerve or the labyrinth on one side. In the normal condition, the two labyrinths are connected to a functional unit in coplanar pairs of semicircular canals working in a push-pull mode (during head rotation, one side is excited and the other side is inhibited, and vice versa). If the head is not moving, the two labyrinths generate a resting firing rate of the vestibular nerve, which is exactly equal on both sides. In AUV, the resting firing frequency is drastically reduced on the affected side, thereby creating a tonic imbalance between the normal activity on the healthy side and the damaged side. The resulting imbalance mimics a permanent rotation towards the healthy side, inducing a spontaneous horizontal nystagmus beating towards the healthy side together with rotational vertigo and postural imbalance, with the tendency to fall toward the affected side [16].

An intense and prolonged vestibular crisis with peripheral characteristics and associated neuro-vegetative symptoms is generally attributed to a viral disease of the labyrinth (vestibular neuritis). However, AUV pathogenesis is unknown, except in rare cases, such as herpes zoster oticus, or viralassociated labyrinthopathy in the course of a systemic viral infection (such as measles, mumps, and rubella).

Despite its uncertain pathogenesis, AUV accompanying vertigo may be troublesome for the patient, and therefore, the first steps when addressing AUV are physical examination and symptomatic treatment with vestibular suppressants in order to alleviate the patient's neuro-vegetative symptoms (predominantly nausea and vomiting) and intense rotatory vertigo.

Vestibular suppressants are drugs that reduce subjective symptoms and nystagmus evoked by vestibular imbalance induced by the unilateral vestibular hypofunction. Vestibular suppressants include anticholinergics, antihistamines, benzodiazepines, and calcium channel antagonists. Some of these drugs may have a combined effect. For example, while meclizine (widely used in the USA) acts almost exclusively as an antihistamine, dimenhydrinate acts both as an $\mathrm{H}_{1}$ antagonist and as an anticholinergic drug. A recent clinical trial reported an equivalence between dimenhydrinate and diazepam in treating acute vertigo in an emergency medicine setting [17]. However, dimenhydrinate induces less sedation than benzodiazepines, and for this reason, it is preferred as initial treatment, especially in the older patient. Actually, older patients treated with benzodiazepines are more likely to present side effects (e.g., severe drowsiness, dizziness, confusion, clumsiness or unsteadiness) and age-related kidney issues, which may advise caution and an adjustment of therapy dose and duration. Although meclizine and promethazine also display antiemetic activity, administration of antiemetic compounds (such as ondansetron, an antagonist of the 5-HT3 receptors, or metoclopramide, a dopaminergic antagonist) could be proposed to reduce the neuro-vegetative symptoms accompanying AUV. These drugs could be generally administered per os except in case of excessive vomiting, for which intravenous administration is recommended. However, all symptomatic therapies must be reduced after the first 1 or 2 days, in order to avoid an impairment of the central compensatory mechanism [18]. The recovery of static and dynamic symptoms after AUV is related to:

1. Restoration of peripheral function.

2. Habituation; hence, a progressive reduction of the vestibular lesion-induced asymmetry by repetition of the triggering signals.

3. Adaptation; since balance is determined by the integration of vestibular, visual, and somatosensory cues, the lost vestibular function could be replaced by new operating modes using the other sensory cues as a source of possible sensory reweighting $[19,20]$.

Therefore, immediately after the acute phase of AUV, the use of a vestibular suppressant could lead to amplification of the vestibular imbalance and subsequent persistence of the symptoms rather than to their reduction.

Among calcium channel antagonists, cinnarizine is more commonly used and studied compared to flunarizine. It has additional antihistaminic and anticholinergic effects, and it 
has demonstrated a positive effect in the treatment of vertigo [21]. Moreover, when cinnarizine is used in combination with dimenhydrinate, its efficacy in reducing vertigo and neuro-vegetative symptoms remarkably increases, surpassing betahistine's [22-24].

With respect to betahistine, both preclinical and clinical studies have suggested a wide range of potential effects. Firstly, it modulates histaminergic neurotransmission by partially agonizing the activity of the $\mathrm{H}_{1}$ receptor, but it has, however, more potent antagonistic properties on the histamine $\mathrm{H}_{3}$ receptor, inducing an overall increase in histamine turnover and release $[25,26]$. Secondly, it affects neuronal excitability and spike generation in lateral and medial vestibular nuclei. It has been reported that histamine induces an excitatory modulation by depolarizing both spontaneous firing neurons and silent neurons in the rat inferior vestibular nucleus via the histamine $\mathrm{H}_{1}$ and $\mathrm{H}_{2}$ receptors [27]. Moreover, several studies indicated that the histamine $\mathrm{H}_{3}$ receptor may play a role in vestibular compensation, behavioral recovery, and reduction of symptoms [28, 29]. Thirdly, betahistine produces vascular effects on both the cochlea and the brain $[30,31]$. Finally, it is possible that the betahistine antivertigo activity is firstly achieved by betahistine itself and then sustained by its metabolite aminoethyl pyridine [32].

A consistent number of studies support the positive impact of betahistine on vertigo symptoms [33, 34]. On the other hand, the heterogeneity registered among the applied methodologies and patient selection in these studies do not allow one to draw a definite conclusion on the positive role of betahistine in the treatment of acute vertigo and in the improvement of vestibular compensation after AUV. Ideally, drugs capable of enhancing vestibular compensation may be prescribed in order to induce an acceleration of functional recovery, especially in those patients with reduced mobility, which may prevent a successful vestibular physical rehabilitation. For this purpose, some reports indicate that betahistine [26] or Ginkgo biloba extract, an antioxidant agent with mild antiplatelet activity [35], seem to induce an acceleration of functional recovery. However, the use of betahistine in the routine treatment protocol of patients with AUV may be considered as an option, on the basis of a Cochrane review affirming that low-quality evidence suggests that in patients suffering from vertigo from different causes, there may be a positive effect of this drug in terms of reduction in vertigo symptoms [36].

Actually, the use of antivertigo medications with vestibular suppressant activity (Table 2) should be restricted to the first days after the onset of symptoms, as they act as sedatives and may delay central compensation of the peripheral vestibular deficit. Thus, the treatment strategy for AUV entails the use of as few medications as possible and encouraging the patient to increase his or her physical activity as much as it is tolerated. Furthermore, in older people, the side effects associated with these drugs could be potentially

Table 2 Vestibular suppressants and their side effects

\begin{tabular}{|c|c|c|c|}
\hline Pharmacological class & Activity & Examples of drugs & $\begin{array}{l}\text { Principal adverse reactions in vertigo } \\
\text { setting }\end{array}$ \\
\hline Phenothiazines & $\begin{array}{l}\text { Anticholinergics with sedative and } \\
\text { antiemetic activity due to their } \\
\text { action on CTZ }\end{array}$ & $\begin{array}{l}\text { Promethazine (also antihistaminic } \mathrm{H}_{1} \\
\text { activity) } \\
\text { Prochlorperazine: prominent } \\
\text { antiemetic activity } \\
\text { Thiethylperazine: prominent } \\
\text { antiemetic activity }\end{array}$ & $\begin{array}{l}\text { Extrapyramidal side effects (dyskine- } \\
\text { sia): should not be associated with } \\
\text { neuroleptics and anticonvulsants }\end{array}$ \\
\hline Anticholinergics & $\begin{array}{l}\text { Strong central inhibition, prominent } \\
\text { activity on neurovegetative symp- } \\
\text { toms (nausea and vomit) }\end{array}$ & $\begin{array}{l}\text { Scopolamine } \\
\text { Dimenhydrinate } \\
\text { Meclizine (antihistamine, } \mathrm{H}_{1} \text { blocker) }\end{array}$ & $\begin{array}{l}\text { Sedating } \\
\text { Dry mouth } \\
\text { Urinary retention } \\
\text { Precaution in glaucoma } \\
\text { Precaution in prostatic enlargement } \\
\text { Tachyarrhythmia }\end{array}$ \\
\hline Benzodiazepines & $\begin{array}{l}\text { Vestibular suppressants } \\
\text { Anxiolytics } \\
\text { Favor cerebellar suppressant activity }\end{array}$ & $\begin{array}{l}\text { Diazepam } \\
\text { Lorazepam }\end{array}$ & $\begin{array}{l}\text { Strong sedation } \\
\text { Respiratory depressant } \\
\text { Precaution in glaucoma } \\
\text { Drug dependency }\end{array}$ \\
\hline Antidopaminergics & Antiemetics & $\begin{array}{l}\text { Metoclopramide } \\
\text { Levosulpiride: selective activity on } \\
\text { CTZ }\end{array}$ & $\begin{array}{l}\text { Extrapyramidal side effects } \\
\text { Hormonal alterations (prolactin) }\end{array}$ \\
\hline Calcium channel blockers & $\begin{array}{l}\text { Calcium channel blockers } \\
\left.\text { Antihistamines ( } \mathrm{H}_{1} \text { blockers }\right)\end{array}$ & $\begin{array}{l}\text { Cinnarizine } \\
\text { Flunarizine (cinnarizine derivative) }\end{array}$ & $\begin{array}{l}\text { Drowsiness } \\
\text { Depression } \\
\text { Parkinsonism } \\
\text { Weight gain }\end{array}$ \\
\hline
\end{tabular}

$C T Z$ chemoreceptor trigger zone 
dangerous, especially when taking into consideration possible interactions with other chronic treatments, frequently encountered in older patients. Therefore, some drugs are to be used with particular caution in the older population. For example, prolonged treatment with cinnarizine may induce depression and parkinsonism, while antihistamines are associated with sedation and drowsiness and may have a negative impact on daily function, especially in older patients, who are more affected by reduced mobility and more prone to the risk of falling. These observations are especially relevant in frail older patients in whom AUV (and other forms of acute vertigo such as benign paroxysmal positional vertigo [BPPV]) induces an increased risk of disability.

Therefore, once vertiginous and neuro-vegetative symptoms have subsided, it is advisable to suspend the pharmacological treatment in order for the central compensation to be established. As already stated, this principle is to be taken into consideration especially when treating older patients, while bearing in mind that age should not prevent a successful physical vestibular rehabilitation.

Both viral and vascular factors may contribute to AUV presentations. On the basis of a viral origin of AUV, a short course of corticosteroids may be indicated [37], although a very recent systematic review and meta-analysis concluded that there is insufficient evidence to support their use in AUV [38]. On the contrary, a retrospective study demonstrated that patients receiving a steroid treatment (methylprednisolone $1 \mathrm{mg} / \mathrm{kg}$ for 5 days with an additional 5 days of $0.5 \mathrm{mg} /$ $\mathrm{kg}$ ) showed better results in terms of vestibular recovery and symptomatic relief/improvement compared to patients receiving non-glucocorticoid treatment [39]. Besides these controversial results, it has been suggested that steroid treatment started within $24 \mathrm{~h}$ of onset of AUV results in better recovery of vestibular function than treatment between 25 and $72 \mathrm{~h} \mathrm{[40].} \mathrm{Especially} \mathrm{in} \mathrm{older} \mathrm{patients,} \mathrm{this} \mathrm{therapeutic}$ option should be evaluated carefully due to the risk of possible adverse effects of steroids such as infections, blood clots, fractures, hyperglycemia, and hypertension.

In older patients AUV could be related to vascular insufficiency, but its presentation does not differ, and it is hard to distinguish from other forms of AUV based solely on clinical evidence. Anyway, it is indicated to control vascular risk factors through primary and secondary prevention strategies, given the possible simultaneous presence of cardiac and brain vascular comorbidities. It is possible that the first organ to be affected by a compromised vascular system is actually the labyrinth, given its terminal vascularization and its high metabolic needs. Therefore, in some cases, the first vertiginous crisis constitutes an alarm signal, which, if promptly diagnosed, may help to prevent subsequent vascular episodes, such as strokes or myocardial infarctions.

\subsection{Benign Paroxysmal Positional Vertigo (BPPV)}

BPPV is the most common cause of vertigo, affecting approximately $20 \%$ of all cases [41]. While BPPV may arise at any time of life, it manifests more frequently in adults and older patients, with a peak incidence between the 5 th and 7 th decade of life, probably due to the higher risk of otoconia detachment with age [42].

The most credited etiology involves the mechanical detachment of otolithic fragments from the utricular macula and their migration into one of the semicircular canals. Being mechanical in origin, it is therefore not susceptible to pharmacotherapy, and its treatment of choice is constituted by physical therapy. Repositioning maneuvers can successfully free the affected semicircular canals from the displaced otoconia in almost the totality of patients, even if performance of this treatment in the older population could be challenging because of some orthopedic problems limiting the range of motion in the cervical spine. Also, a previous history of vertebrobasilar insufficiency, stroke, or cervical spine instability should suggest caution in performing extension of the cervical spine [43, 44].

Vestibular suppressant medications are not routinely recommended for treatment of BPPV. Patients who are severely symptomatic (with accompanying autonomic symptoms such as nausea and vomiting) or patients who become severely symptomatic after a repositioning maneuver could benefit from a short-term period of treatment with vestibular suppressant and/or antiemetics [45, 46]. In patients with severe forms of BPPV, drugs such as dimenhydrinate or betahistine may have a role in the short-term control of neuro-vegetative symptoms (nausea, pallor, vomiting, sweating), while antiemetics such as ondansetron may be helpful in preventing vomiting associated with diagnostic or therapeutic maneuvers. However, it is important to highlight the fact that neuro-vegetative symptoms tend to subside after the first few days and that prolonged pharmacotherapy may not provide any additional positive effect. As already described for AUV, vestibular suppressants' side effects include sedation, urinary retention, and (especially in older adults) psychomotor retardation, which may contribute consistently to the risk of falling, especially immediately after a liberation maneuver or in the case of a balance crisis due to the late displacement of otolithic fragments. Moreover, older patients are more likely to experience drug interactions, for example, with other drugs affecting some CNS activity. It is therefore strongly advised to limit the use of drugs in the treatment of BPPV only to selected cases, such as patients particularly sensitive to motion sickness. In common clinical practice, the use of a prophylactic pharmacotherapy before a repositioning maneuver is rare, especially in the older population. 
Pharmacotherapy in BPPV is undertaken for the following:

Residual dizziness: Up to two-thirds of patients may perceive a prolonged and handicapping instability, lightheadedness, and malaise, also known as "residual dizziness" [47]. Usually the symptoms resolve in 6-20 days, but some patients may still be symptomatic after 1 or 2 months [48]. These symptoms may negatively affect the patients' quality of life and may prevent them from carrying out daily activities. An impaired postural control may contribute to falling and psychological distress. Older patients are commonly affected by a deterioration of the visual and proprioceptive systems, but also by a global impairment of the vestibular function. This age-related decline of the vestibular system may contribute to a decrease in balance compensatory ability in older patients with peripheral vestibular deficit and may be related to the greater incidence of residual dizziness in this group. The proposed pharmacotherapies for residual dizziness include benzodiazepines [49], dimenhydrinate [50], and betahistine [51]. However, as stated in Sect. 2.1, the administration of such drugs in older patients needs extreme caution and should be restricted to a few days and only in cases with relevant symptoms. Nevertheless, a successful residual dizziness treatment may be of particular significance regarding the prevention of the evolution towards a condition of chronic dizziness, in which a psychological component may favor a subsequent evolution towards persistent postural-perceptual dizziness (PPPD). Finally, early recognition and prompt treatment of BPPV are of fundamental importance in order to reduce the incidence of residual dizziness, especially in psychiatric or older patients at risk of falling.

Prevention: BPPV is known to recur frequently. Reported rates of recurrence in BPPV vary considerably, ranging from 16 to $50 \%$ [52,53], and some reports correlated an increased rate of recurrence with aging $[54,55]$. In patients with recurrent BPPV, vitamin D deficiency was shown to be a relevant cofactor [56]. Other factors include sex and age, as recurrent BPPV is more frequent among females and older patients [57], with postmenopausal women being more affected [58]. The high prevalence of osteoporosis among this latter group induced a correlation between BPPV (especially in its recurrent form) and osteoporosis. On these bases, vitamin D supplementation has been suggested to decrease recurrent attacks of BPPV. Interestingly, some recent prospective, randomized, and controlled trials have indicated a preventive effect of vitamin D supplementation on the occurrence rate of BPPV [59]. Based on this evidence vitamin D supplementation may be considered in patients with frequent relapses of BPPV and reduced vitamin D serum levels.

\subsection{Ménière's Disease (MD)}

A higher prevalence of Ménière's disease (MD) in patients over 65 years has been reported in the European population [60], both for a reactivation of MD and for a "de novo" manifestation. MD in older patients shows some peculiar features: firstly, a higher incidence in women and, secondly, an increased risk for the so-called Tumarkin's otolithic crises, which are defined as sudden and unpredictable falls without loss of consciousness, caused by an acute stimulation of the otolithic organ [61]. Also, in the case of MD, polymedication, often administered in older patients due to the presence of other comorbidities, constitutes a challenge for the treatment of the balance disorder.

Regarding acute phase therapy, MD does not differ from AUV. The therapeutic goal is to help the patient to recover from the acute phase. Prolongation of therapy should not be needed in MD, as the vertigo attacks do not usually exceed $24 \mathrm{~h}$ in duration, including the post-critical malaise.

Currently, a strongly effective preventive treatment is not known. Considering MD as a heterogeneous category of diseases with the same phenotypic presentation but multiple pathogenetic mechanisms, prevention should ideally consider the specific etiology. Consequently, migraineassociated MD should be prevented by migraine-preventing therapies, and vascular MD should be prevented through primary prevention of cardiovascular risk factors and therapies in order to improve local blood perfusion and circulation. In cases of autoimmune labyrinthopathy (including Cogan syndrome and delayed endolymphatic hydrops), preventive therapy is constituted by steroids or immunosuppressive medications. Despite the fact that dietary interventions through low-sodium or hyper-hydrating meal plans are advised by practitioners, at the moment, no scientific evidence has been reported [62].

In most cases, antivertigo drugs such as betahistine give good results, with minor secondary effects. On the other hand, neuroleptics and antihistamines are more difficult to manage because of their relevant side effects, such as parkinsonism and depression.

In a recent multicentric study, betahistine was proposed as the first-choice medication for the intercritical phase of MD, with a variable dosage between 32 and $48 \mathrm{mg} /$ day, which can be adjusted over the course of the treatment. It is advisable to prescribe betahistine for at least 3 months for patients who have had one to three attacks in the previous 6 months. However, it is possible to extend the treatment on the basis of the patient's conditions [63]. The panel of experts agreed that betahistine efficacy depends neither on the gender nor on the age of MD patients. However, 
betahistine's positive effects on the whole MD clinical picture still remain controversial. As a matter of fact, no compelling evidence of its efficacy has been produced yet, and a prospective, controlled clinical trial with betahistine dosages of $48 \mathrm{mg} /$ day and $48 \mathrm{mg}$ three times a day failed to show a significant therapeutic effect against placebo [64]. On the other side, the latest Cochrane review on the efficacy of betahistine in MD [65] and two meta-analyses $[33,66]$ concluded that betahistine is acceptable to use. A German experience, applying the rationale of betahistine's rapid metabolism by intestinal and hepatic monoamine oxidase B enzyme, confirmed the possibility of increasing progressively (on the basis of the beneficial effect) the dosage of this drug up to $480 \mathrm{mg} /$ day in patients who do not respond to a lower dosage, in the same way as the therapeutic approach in epilepsy using carbamazepine [67].

Among the pharmacological therapies proposed, diuretics represent the most used category for the treatment of MD [68]. Diuretics have been in use in the treatment of MD for several decades and are thought to reduce the degree of endolymphatic hydrops by reducing the extracellular volume and consequently inducing a decrease of the endolymphatic pressure and volume, either by increased drainage of endolymph or through a reduction in its production at the stria vascularis. Despite the absence of specific experimental and clinical evidence of diuretics' effectiveness [69, 70], some studies support diuretic use, with this helping approximately two-thirds of patients achieve substantial control of vertigo attacks when used in association with dietary (low-salt diet and increase of water intake) and lifestyle modifications [71, 72]. The use of diuretics and/or betahistine could be offered as an option for maintenance therapy to reduce symptoms or prevent MD attacks [73]. Among the different classes of diuretics (Table 3), the most used are hydrochlorothiazide (it should be avoided or used cautiously in patients with hypotension, renal disease, diabetes mellitus, and gout), triamterene, and acetazolamide. The use of acetazolamide could have more indications in MD patients who have underlying migraines and in patients with bilateral MD. The rationale behind this is that acetazolamide is not only a diuretic, but it also causes cerebral vasodilation and carbonic anhydrase inhibition. Furthermore, acetazolamide seems to significantly reduce hydrops, as seen by magnetic resonance [74]. Finally, in older patients suffering from MD, diuretics may produce significant collateral effects, and therefore, their usage should be limited to selected cases.

The finding of glucocorticoid receptors in various structures of the inner ear, especially within the stria vascularis [75], encouraged the use of oral corticosteroids, likewise taking into consideration the high prevalence of autoimmune disorders in MD and the role of inflammation. The beneficial effects of intratympanic (IT) steroids could be due to the anti-inflammatory effects of both methylprednisolone and dexamethasone. Steroids can also affect the ion and fluid homeostasis of the inner ear by induction of mineralocorticoid receptor-mediated genes [76] and by control of the aquaporin channels [77]. Finally, cochlear blood flow may be positively affected by topical application of steroids [78]. Only a few reports have investigated the effects of oral steroids in MD, with questionable results $[79,80]$. Recently, the use of IT steroids has overtaken oral administration thanks to the absence of many undesirable side effects or contraindications; this observation is particularly of note when approaching an older MD patient in whom the risk of possible adverse effects such as infections,

Table 3 Diuretics used in the treatment of MD's intercritical phase

\begin{tabular}{|c|c|c|c|}
\hline Pharmacological class & Activity & Examples of drugs & Side effects \\
\hline Thiazides & $\begin{array}{l}\text { Inhibit reabsorption of luminal sodium by blocking the } \mathrm{Na}^{+} / \mathrm{Cl}^{-} \\
\text {channel in the kidney's distal convoluted tubule }\end{array}$ & $\begin{array}{l}\text { Chlorthalidone } \\
\text { Hydrochlorothiazide }\end{array}$ & $\begin{array}{l}\text { Hypokalemia } \\
\text { Hyperuricemia } \\
\text { Hyperglycemia }\end{array}$ \\
\hline Potassium-sparing diuretics & Inhibit renal $\mathrm{Na}^{+} / \mathrm{K}^{+}$exchange & Spironolactone & $\begin{array}{l}\text { Hyperkalemia } \\
\text { Hormonal } \\
\text { alterations } \\
\text { (estrogenic } \\
\text { effects) }\end{array}$ \\
\hline Loop diuretics & Inhibit renal co-transport by blocking the $\mathrm{Na}^{+}-\mathrm{K}^{+}-2 \mathrm{Cl}^{-}$symporter & Furosemide & $\begin{array}{l}\text { Hypovolemia } \\
\text { Hypotension } \\
\text { Hypokalemia }\end{array}$ \\
\hline Carbonic anhydrase inhibitors & Inhibit $\mathrm{H}^{+}$secretion and promote $\mathrm{Na}^{+}$and $\mathrm{K}^{+}$excretion & Acetazolamide & $\begin{array}{l}\text { Gastrointestinal } \\
\text { disturbances } \\
\text { Metabolic } \\
\text { acidosis } \\
\text { Nephrolithiasis }\end{array}$ \\
\hline
\end{tabular}

$M D$ Ménière's disease 
blood clots, fractures, hyperglycemia, and hypertension is remarkable. At this time, although there have been some favorable reports [81-83], the effect of IT steroid treatment in MD is questionable, especially in terms of vertigo control $[84,85]$. Despite the fact that a general consensus on MD therapy has not been reached, the use of IT gentamicin injections in patients with resistant forms has been accepted by most authors [86-88], while IT steroidal injections do not seem to be equally effective, at least in terms of vertigo control [88-90]. Gentamicin possesses toxic activity against the inner ear hair cells, especially against type 1 vestibular hair cells, and the aim of IT gentamicin is to obtain a long-lasting, non-fluctuating, peripheral vestibular hypofunction capable of being centrally compensated. Given the considerable side effects of IT gentamicin, such as dizziness and hearing loss, its usage in older adults should be considered carefully. For these reasons, IT gentamicin is indicated almost exclusively in patients who have not responded positively to medical therapy and who suffer from unilateral MD, with good hearing in the healthy ear. Obviously, young patients are the best candidates for an easier achievement of vestibular compensation. The great advantage of labyrinthine ablation with gentamicin is based on the minimally invasive nature of the procedure and on the demonstration that it is not necessary to achieve total destruction of the neurosensory structures of the vestibule to achieve the desired therapeutic effect [91].

However, no drug seems able to delay or block hearing loss or tinnitus progression in MD [92]. Evaluation of the efficacy of an MD therapy is complicated by the fact that the natural history of the disease involves a decrease in the frequency of crises, due to a reduction in vestibular function.

Regarding MD in the older population, two types of cases can be identified.

1. Recent and new MD onset in older patients.

This clinical picture is generally rare, and strongly correlates with a vascular origin of symptoms. In this case, it may be useful to prescribe primary and secondary prevention to improve local blood circulation.

2. Already diagnosed MD, in a quiescent state.

In this picture, vertigo attacks have subsided, but general postural instability remains as a consequence of the vestibular deficit produced by past crises. In such cases, pharmacotherapy does not help, while physical therapy and mobilization are encouraged in order to favor balance compensatory mechanisms.

\section{Central Vertigo and Dizziness}

Both vestibular migraine (VM) and vascular vertigo are CNS pathologies, but they can also affect the peripheral vestibular receptors. It is important to highlight the fact that migraine is also a vascular risk factor and that the labyrinth is a highrisk area for vascular accidents, in a way that its disease may precede the extension of vascular pathologies to other organs and apparatuses.

\subsection{Vestibular Migraine (VM)}

Migraine-associated vertigo should not be necessarily treated pharmacologically. As a matter of fact, once the patient has been properly instructed on the diagnosis and prognosis of their disease, it is possible that the frequency and intensity of vertiginous episodes are so low that a prophylactic therapy is not required.

It may be possible that in older patients (especially in postmenopausal women), a variation in the clinical picture occurs, with the onset, remittance, or variation in the features of vertigo, with the consequent need to adjust the therapeutic plan [93]. VM vertiginous attacks are not generally treated pharmacologically, but in the case of frequent (at least one episode every 2-3 months) or disabling crises, a prophylactic therapy may be indicated.

The most used classes of drugs include beta-blockers, calcium channel blockers, and antidepressants (Table 4) [94].

\subsubsection{Beta-Blockers (Propranolol, Atenolol)}

Contraindications of beta-blockers include bronchopathies, cardiopathies, vasculopathies, diabetes, hypotension, and asthenia. These drugs are particularly effective in cases of VM with concomitant arterial hypertension and/or tachycardia. They must be administered with medical control, as postural instability syndromes are frequently recorded [95].

\subsubsection{Calcium Channel Blockers (Flunarizine, Cinnarizine)}

Calcium channel blockers [96] are contraindicated in the case of hypotension, depression, and tremor or in overweight patients. However, it may be that due to their association with the development of parkinsonism, dyskinesia and dystonia, long-term usage should be limited to cases presenting a positive benefit/risk ratio [97]. Particularly interesting is the observation that in the 3 months following suspension of a calcium channel blocker treatment, side effects tend to remit, while beneficial therapeutic effects remain. This observation may constitute supporting evidence in favor of 
Table 4 Different classes of drugs used for pharmacological prophylaxis of VM

\begin{tabular}{|c|c|c|}
\hline & Common side effects & Indications \\
\hline \multicolumn{3}{|l|}{ Beta-blockers } \\
\hline $\begin{array}{l}\text { Propranolol } \\
\text { Atenolol }\end{array}$ & $\begin{array}{l}\text { Hypotension, Fatigue, } \\
\text { Bronchial constriction, } \\
\text { difficulties sleeping or nightmares } \\
\text { Precaution in diabetes }\end{array}$ & $\begin{array}{l}\text { Hyperten- } \\
\text { sion, tachy- } \\
\text { cardia }\end{array}$ \\
\hline \multicolumn{3}{|c|}{ Calcium channel blockers } \\
\hline $\begin{array}{l}\text { Cinnarizine } \\
\text { Flunarizine }\end{array}$ & $\begin{array}{l}\text { Hypotension } \\
\text { Depression } \\
\text { Tremor } \\
\text { Weight gain }\end{array}$ & $\begin{array}{l}\text { Vasculopathy } \\
\text { Insomnia } \\
\text { Anxiety }\end{array}$ \\
\hline \multicolumn{3}{|l|}{ Antidepressants } \\
\hline $\begin{array}{l}\text { Amitriptyline } \\
\text { Fluoxetine }\end{array}$ & $\begin{array}{l}\text { Sedation, orthostatic hypotension, dry mouth, weight gain, constipation } \\
\text { Precaution in prostate enlargement, kidney disease and glaucoma }\end{array}$ & Depression \\
\hline \multicolumn{3}{|l|}{ Antiepileptics } \\
\hline $\begin{array}{l}\text { Sodium valproate } \\
\text { Topiramate }\end{array}$ & $\begin{array}{l}\text { Paresthesia, somnolence, cognitive dysfunction, tremors } \\
\text { Precaution in kidney and liver disease }\end{array}$ & Epilepsy \\
\hline \multicolumn{3}{|l|}{ Diuretics } \\
\hline Acetazolamide & $\begin{array}{l}\text { Paresthesia, nausea, sedation, hypokalemia } \\
\text { Precaution in kidney disease }\end{array}$ & \\
\hline
\end{tabular}

$V M$ vestibular migraine

calcium channel blocker cyclic prescription [98], and this approach may be especially useful in older patients, who are more predisposed to the development of parkinsonism [99].

\subsubsection{Antidepressants (Amitriptyline, Fluoxetine)}

In the case of concomitant depression and VM, antidepressants are indicated and preferred to calcium channel antagonists and beta-blockers. Their impact on cardiac kinetic activity seems to be less evident with a lower dosage [100].

\subsubsection{Anticonvulsants (Sodium Valproate, Topiramate)}

Topiramate is an anticonvulsant with GABA- $\alpha$ agonistic properties acting through central modulation of GABA and glutamate level. This drug showed beneficial effects for prophylactic treatment for VM [101]. Valproic acid was also shown to be effective in decreasing the number of vertiginous attacks, although it seems to be less active than other drugs (flunarizine or beta-blockers) in the decrease in vertigo severity [102].

\subsubsection{Diuretics (Acetazolamide)}

The use of this drug (a carbonic anhydrase inhibitor) in treating VM started from its demonstrated efficacy for the therapy of episodic ataxia type 2 and familial hemiplegic headache. The vestibular symptoms encountered in these two diseases are supposed to be caused by an ion channel deficit [103], and the efficacy of acetazolamide could be attributed to the possible involvement of neuronal ion channels [104] in the pathogenesis of VM. In a recent retrospective study, the use of acetazolamide correlated with a significant decrease in the frequency and severity of vertigo attacks [105].

In the treatment of VM, antidepressants should be started at a low dosage and increased until the minimum effective dosage for maintenance is found. Also, in the case of suspension, the dosage should be tapered slowly and gradually. Before evaluating the efficacy of antidepressants for VM, at least 3 months of therapy should have passed. The treatment is considered effective if the frequency of crises is reduced at least by $50 \%$. When possible, it is advisable to check for triggering factors, such as physical exercise, variation in sleep patterns, stress, or certain foods (chocolate, cheese, alcohol). Often, VM patients also present motion sickness, and this should be considered when performing diagnostic exams, planning functional rehabilitation, or advising the patient about lifestyle modifications.

To date, no significant double-blinded, randomized controlled trials for the treatment of VM have been published. As a matter of fact, the data available have been included in uncontrolled clinical retrospective studies, which do not provide robust evidence in favor of a given VM treatment [94]. An alternative emerging non-pharmacological treatment for chronic pain, certain forms of epilepsy, and tinnitus has been recently developed. It has been suggested that this 
procedure could correct the imbalance between parasympathetic and sympathetic nervous systems [106]. Noninvasive transcutaneous vagus nerve stimulation has also been proven to be effective, through stimulating the auricular branch, in reducing vertigo in acute VM episodes [107]. Probably the benefits of this treatment are connected to the inhibition of the firing rate of trigeminocervical neurons, inducing a modulation of the trigemino-vestibulo-vagal connections involved in migraine pathophysiology [108].

\subsection{Vascular Vertigo (VV)}

As with VM, VV also presents a double pathogenesis, both central and peripheral. The labyrinth is a neurosensorial perceptive organ with high oxidative metabolic demands, which is, however, perfused by thin vessels with no collateral vascularization. This anatomic configuration puts the labyrinth at risk for ischemia in such a way that in the case of systemic vascular impairment, it is usually the first organ to be affected.

Excluding severe strokes of vascular origin affecting the cerebellum or the brainstem, which require specific treatments in stroke units, VV is frequently seen in clinical practice, especially in older patients with recurrent vertigo, often associated with other CNS symptoms, such as cognitive impairment, ataxia, and mood disturbances, but also alone. Therapy should focus on reducing potential risk factors (diabetes, dyslipidemia, hypertension, smoking habit, sedentary lifestyle) and on planning secondary prevention in order to improve local microvascular perfusion.

Antiplatelet drugs (also known as antiaggregants) are among the most prescribed drugs. They are, however, associated with a higher hemorrhagic risk, and therefore, alternative medications have been proposed.

Sulodexide has a similar effect to heparin, with fewer severe side effects and without the need for coagulation control, unless it is co-prescribed with other drugs with a risk for hemorrhagic events [109-111]. Also mesoglycan [112] has been proposed for long-term prophylactic therapy of VV, with the additional goal of preventing the extension of the vascular deficit to other organs. Nimodipine, a calcium channel blocker used in the prevention of vasospasm secondary to subarachnoid hemorrhage, has shown some efficacy in the treatment of vertigo and dizziness frequently observed in older patients with cerebrovascular disease affecting areas and neural pathways in the CNS involved in vestibular compensation [21]. Nimodipine, by facilitating perfusion and oxygenation of human brain hypoxic areas [113], showed favorable effects on age-related cerebrovascular disorders [114], representing a possible choice in the treatment of vertigo of vascular origin in older patients [115].

Among the central causes of dizziness in the older population, leukoaraiosis (LA) has been generating interest among researchers in recent years. LA is a common radiological finding in older patients, and it is commonly associated with multiple clinical findings, such as cognitive impairment, gait disturbances, falls, and dizziness [116]. LA is a purely descriptive radiological term that is related to cerebral small vessel disease (cSVD) [117], and it is commonly associated with cardiovascular risk factors, especially hypertension [118]. Ahmad and colleagues [119] report that the severity of cSVD is higher in elderly patients with no specific cause for their dizziness, and therefore, they postulated that CSVD may induce dizziness and increased fall risk either because patients perceive a degree of objective unsteadiness or because of a cortical-subcortical disconnection syndrome secondary to disruption of white matter tracts involved in gait and balance control. As a matter of fact, older patients with dizziness for whom a definitive diagnosis has not been yet determined despite extensive clinical and vestibular assessments should undergo brain imaging in order to assess their level of cSVD. On the other hand, clinicians should be cautious when ascribing dizziness solely to the presence of mild or moderate cSVD, as easily treatable peripheral vestibular diseases, which still affect the geriatric population with high frequency, could be missed [116].

Regarding the pathogenesis of LA, endothelial dysfunction and oxidative stress have been hypothesized to play a central role. According to pathological findings, endothelial dysfunction may be significantly more widespread than neuroradiological evidence alone would suggest [120].

The current treatment for cSVD-associated dizziness involves preventive measures, such as control of vascular comorbidities and risk factors (especially by lowering blood pressure), together with lifestyle interventions, such as an encouragement to increase physical activity and aerobic exercises. Proposed new therapeutic approaches include endothelin antagonists, neurotrophins, peroxisome proliferator-activated receptor- $\gamma$ agonists and prostacyclin mimics [121]. In patients with cSVD and dizziness, remarkable results have been reported using sulodexide [122]. Moreover, polyphenol supplementation seems to reduce oxidative stress load in patients with a pre-existing imbalance, and as a consequence, it improves dizziness symptoms [120]. However, a double-blind, placebo-controlled study is needed to confirm the preliminary results reported in the abovementioned studies.

\section{Functional Dizziness}

Functional dizziness indicates vestibular-like disorders of psychogenic or somatoform origin that often occur in association with panic disorder, generalized anxiety disorder, and agoraphobia. In recent years, this clinical picture has been named "persistent postural-perceptual dizziness" (PPPD) in 
order to reflect its main diagnostic criteria of persistent nonvertiginous dizziness, unsteadiness and non-spinning vertigo that are exacerbated by postural challenges, and perceptual sensitivity to space-motion stimuli [123]. PPPD cannot be attributed to a specific structural organic lesion within the vestibular system; rather, it is a maladaptive dysfunction of balance control and vestibular processing. Selective serotonin reuptake inhibitors (SSRIs) and serotonin-norepinephrine reuptake inhibitors (SNRIs) are commonly recommended for chronic functional dizziness with and without psychiatric comorbidities [123] and can be successfully offered to older patients in combination with vestibular rehabilitation, whose role is to desensitize an "oversensitive" balance control system with the use of habituation exercises and relaxation techniques [124]. Some studies have reported positive effects with the use of sertraline, as evaluated by an improvement in subjective outcome measures between 55 and $67 \%$ [125]. However, further validation by randomized, controlled, and blinded trials is needed to provide more robust evidence regarding this matter. In older patients with functional dizziness, benzodiazepine-like drugs should be prescribed with caution, considering the risk of sedation during the day and the risk of falls during the night. On the contrary, side effects commonly associated with SSRIs (agitation, anxiety, insomnia, sedation, gastrointestinal issues, sexual dysfunction) do not differ between young and older populations [126].

\section{Conclusions}

Dizziness and vertigo represent common complaints in older adults, with falling a frequent and possibly severe complication. Due to the increasing number of older patients in Western societies, the problem is destined to grow. The increased susceptibility of senior patients to falling may be a consequence of age-related physiological changes and of a higher prevalence of comorbidities that can result in dizziness, vertigo, and imbalance. These symptoms can worsen the already decreased balance capabilities of aged patients and, therefore, increase the risk of falling. Among the major causes of vertigo and dizziness, vestibular disorders play an important role and are currently estimated to account for $48 \%$ of dizziness, as reported by older patients [127]. An early identification of the treatable conditions underlying dizziness in older patients would surely ameliorate the overall outcome.

Since the cause of dizziness in this population is likely to be multi-factorial, its management should be customized and personalized according to each patient's clinical picture and history. However, it is possible to establish some important steps to undertake when approaching an aging patient:
1. Assess the current medication, as some drugs taken to treat different comorbidities could directly affect the vestibular end-organ or cause dizziness and/or orthostatic hypotension.

2. Perform a Dix-Hallpike maneuver in order to check for the presence of BPPV.

3. In the case of acute vertigo, the use of vestibular suppressants should be limited only to the acute phase of the disease in order to avoid any negative effect on functional recovery or central compensation.

4. The choice of pharmacotherapy for vertigo should take into account all the possible side effects and interactions with the currently prescribed drugs.

5. In the majority of patients, it is recommended to encourage physical activity and exercise, as vestibular rehabilitation in any form is extremely effective in treating older adults with vestibular disorders.

\section{Declarations}

Funding Open access funding provided by Università di Pisa within the CRUI-CARE Agreement.

Conflict of interest The authors declare no competing interests.

Availability of data and material Not applicable.

Code availability Not applicable.

Ethics approval Not applicable.

Consent to participate Not applicable.

Consent for publication Not applicable.

Authors' contribution All authors contributed to the first draft of the manuscript. APC revised the manuscript for intellectual content and approved the final version.

Open Access This article is licensed under a Creative Commons Attribution-NonCommercial 4.0 International License, which permits any non-commercial use, sharing, adaptation, distribution and reproduction in any medium or format, as long as you give appropriate credit to the original author(s) and the source, provide a link to the Creative Commons licence, and indicate if changes were made. The images or other third party material in this article are included in the article's Creative Commons licence, unless indicated otherwise in a credit line to the material. If material is not included in the article's Creative Commons licence and your intended use is not permitted by statutory regulation or exceeds the permitted use, you will need to obtain permission directly from the copyright holder. To view a copy of this licence, visit http://creativecommons.org/licenses/by-nc/4.0/. 


\section{References}

1. Neuhauser HK. The epidemiology of dizziness and vertigo. Handb Clin Neurol. 2016;137:67-82. https://doi.org/10.1016/ B978-0-444-63437-5.00005-4.

2. Casani AP, Navari E. Dizziness and prevention of falls in the elderly. Geriatr Care. 2017;3:75-7. https://doi.org/10.4081/gc. 2017.7160.

3. Schlick C, Schniepp R, Loidl V, et al. Falls and fear of falling in vertigo and balance disorders: a controlled cross-sectional study. J Vestib Res. 2016;25:241-51. https://doi.org/10.3233/ VES-150564.

4. Walther L, Kleeberg J, Rejmanowski G, et al. Falls and fall risk factors. Are they relevant in ENT outpatient medical care? HNO. 2012; May:446, 448-56

5. Soto E, Vega R, Seseña E. Neuropharmacological basis of vestibular system disorder treatment. J Vestib Res. 2013;23:119-37. https://doi.org/10.3233/VES-130494.

6. Bisdorff A, Von Brevern M, Lempert T, Newman-Toker DE. Classification of vestibular symptoms: towards an international classification of vestibular disorders. J Vest Res. 2009;19:1-13. https://doi.org/10.3233/VES-2009-0343.

7. Hain TC, Uddin M. Pharmacological treatment of vertigo. CNS Drugs. 2003;17:85-100. https://doi.org/10.2165/00023210200317020-00002.

8. Oghalai JS, Manolidis S, Barth JL, et al. Unrecognized benign paroxysmal positional vertigo in elderly patients. Otolaryngol Head Neck Surg. 2000;122:630-4.

9. Piker EG, Jacobson GP. Self-report symptoms differ between younger and older dizzy patients. Otol Neurotol. 2014;35:873e9e. https://doi.org/10.1097/MAO.0000000000000391.

10. Michel L, Laurent T, Alain T. Rehabilitation of dynamic visual acuity in patients with unilateral vestibular hypofunction: earlier is better. Eur Arch Otorhinolaryngol. 2020;277:103-13. https:// doi.org/10.1007/s00405-019-05690-4.

11. Chimirri S, Aiello R, Mazzitello C, et al. Vertigo/dizziness as a Drugs' adverse reaction. J Pharmacol Pharmacother. 2013;4:S104-9.

12. Kim HA, Bisdorff A, Bronstein AM, et al. Hemodynamic orthostatic dizziness/vertigo: diagnostic criteria. J Vestib Res. 2019;29:45-56. https://doi.org/10.3233/VES-190655.

13. Agrawal Y, Van de Berg R, Wuyts F, et al. Presbyvestibulopathy: diagnostic criteria consensus document of the classification committee of the Bárány Society. J Vest Res. 2019;29:161-70. https://doi.org/10.3233/VES-190672.

14. Regauer V, Seckler E, Müller M, Bauer P. Physical therapy interventions for older people with vertigo, dizziness and balance disorders addressing mobility and participation: a systematic review. BMC Geriatr. 2020;20:494. https://doi.org/10. 1186/s12877-020-01899-9.

15. Kerber KA. Acute vestibular syndrome. Semin Neurol. 2020;40:59-66. https://doi.org/10.1055/s-0039-3402739.

16. Fetter M. Acute unilateral loss of vestibular function. Handb Clin Neurol. 2016;137:219-29. https://doi.org/10.1016/B9780-444-63437-5.00015-7.

17. Shih RD, Walsh B, Eskin B, et al. Diazepam and meclizine are equally effective in the treatment of vertigo: an emergency department randomized double-blind placebo-controlled trial. J Emerg Med. 2017;52:23-7. https://doi.org/10.1016/j.jemer med.2016.09.016.

18. Horak FB, Jones-Rycewicz C, Black FO, et al. Effects of vestibular rehabilitation on dizziness and imbalance. Otolaryngol Head Neck Surg. 1992;106:175-80.
19. Lacour M, Helmchen C, Vidal PP. Vestibular compensation: the neuro-otologist's best friend. J Neurol. 2016;263:54-64. https://doi.org/10.1007/s00415-015-7903-4.

20. Curthoys IS. Vestibular compensation and substitution. Curr Opin Neurol. 2000;13:27-30.

21. Pianese CP, Hidalgo LOV, González RH, et al. New approaches to the management of peripheral vertigo: efficacy and safety of two calcium antagonists in a 12-week, multinational, doubleblind study. Otol Neurotol. 2002;23:357-63. https://doi.org/ 10.1097/00129492-200205000-00023.

22. Cirek Z, Schwarz M, Baumann W, Novotny M. Efficacy and tolerability of a fixed combination of cinnarizine and dimenhydrinate versus betahistine in the treatment of otogenic vertigo: a double-blind randomised clinical study. Clin Drug Investig. 2005;25:377-89. https://doi.org/10.2165/00044011-20052 5060-00003.

23. Hahn A, Sejna I, Stefflova B, et al. A fixed combination of cinnarizine/dimenhydrinate for the treatment of patients with acute vertigo due to vestibular disorders: a randomized, reference-controlled clinical study. Clin Drug Investig. 2008;28:8999. https://doi.org/10.2165/00044011-200828020-00003.

24. Scholtz A-W, Steindl R, Burchardi N, et al. Comparison of the therapeutic efficacy of a fixed low-dose combination of cinnarizine and dimenhydrinate with betahistine in vestibular neuritis: a randomized, double-blind, non-inferiority study. Clin Drug Investig. 2012;32:387-99. https://doi.org/10.2165/ 11632410-000000000-00000.

25. Lacour M, van de Heyning PH, Novotny M, Tighilet B. Betahistine in the treatment of Ménière's disease. Neuropsychiatr Dis Treat. 2007;3:429-40.

26. Tighilet B, Léonard J, Watabe I, et al. Betahistine treatment in a cat model of vestibular pathology: pharmacokinetic and pharmacodynamic approaches. Front Neurol. 2018;9:431. https:// doi.org/10.3389/fneur.2018.00431.

27. Yu L, Zhang X-Y, Cao S-L, et al. $\mathrm{Na}(+)-\mathrm{Ca}(2+)$ exchanger, leak $\mathrm{K}(+)$ channel and hyperpolarization-activated cyclic nucleotide-gated channel comediate the histamine-induced excitation on rat inferior vestibular nucleus neurons. CNS Neurosci Ther. 2016;22:184-93. https://doi.org/10.1111/cns. 12451.

28. Lozada AF, Aarnisalo AA, Karlstedt K, et al. Plasticity of histamine $\mathrm{H} 3$ receptor expression and binding in the vestibular nuclei after labyrinthectomy in rat. BMC Neurosci. 2004;5:32. https:// doi.org/10.1186/1471-2202-5-32.

29. Tighilet B, Trottier S, Mourre C, et al. Betahistine dihydrochloride interaction with the histaminergic system in the cat: neurochemical and molecular mechanisms. Eur J Pharmacol. 2002;446:63-73. https://doi.org/10.1016/s0014-2999(02) 01795-8.

30. Ihler F, Bertlich M, Sharaf K, et al. Betahistine exerts a dosedependent effect on cochlear stria vascularis blood flow in guinea pigs in vivo. PLoS ONE. 2012;7: e39086. https://doi.org/10. 1371/journal.pone.0039086.

31. Bertlich M, Ihler F, Freytag S, et al. Histaminergic H3-heteroreceptors as a potential mediator of betahistine-induced increase in cochlear blood flow. Audiol Neurootol. 2015;20:283-93. https:// doi.org/10.1159/000368293.

32. Botta L, Mira E, Valli S, et al. Effects of betahistine and of its metabolites on vestibular sensory organs. Acta Otorhinolaryngol Ital. 2001;21:24-30.

33. Nauta JJP. Meta-analysis of clinical studies with betahistine in Ménière's disease and vestibular vertigo. Eur Arch Otorhinolaryngol. 2014;271:887-97. https://doi.org/10.1007/ s00405-013-2596-8.

34. Benecke H, Pérez-Garrigues H, Bin Sidek D, et al. Effects of betahistine on patient-reported outcomes in routine practice in 
patients with vestibular vertigo and appraisal of tolerability: experience in the OSVaLD study. Int Tinnitus J. 2010;16:14-24.

35. Lindner M, Gosewisch A, Eilles E, et al. Ginkgo biloba extract EGb 761 improves vestibular compensation and modulates cerebral vestibular networks in the rat. Front Neurol. 2019;10:147. https://doi.org/10.3389/fneur.2019.00147.

36. Murdin L, Hussain K, Schilder AG. Betahistine for symptoms of vertigo. Cochrane Database Syst Rev. 2016;6:CD010696. https:// doi.org/10.1002/14651858.CD010696.pub2.

37. Strupp M, Zingler VC, Arbusow V, et al. Methylprednisolone, valacyclovir, or the combination for vestibular neuritis. N Engl J Med. 2004;351:354-61. https://doi.org/10.1056/NEJMoa0332 80.

38. Leong KJ, Lau T, Stewart V, Canetti E. Systematic review and meta-analysis: effectiveness of corticosteroids in treating adults with acute vestibular neuritis. Otolaryngol Head Neck Surg. 2021. https://doi.org/10.1177/0194599820982910.

39. Batuecas-Caletrio A, Yanez R, Sanchez C, et al. Glucorcorticoids improve acute dizziness symptoms following acute unilateral vestibulopathy. J Neurol. 2015;262:2578-82. https://doi.org/10. 1007/s00415-015-7918-x.

40. Sjögren J, Magnusson M, Tjernström F, Karlberg M. Steroids for acute vestibular neuronitis - the earlier the treatment, the better the outcome? Otol Neurotol. 2019;40:372-4. https://doi.org/10. 1097/MAO.0000000000002106.

41. Brandt T. Vertigo: its multisensory syndromes. 2nd ed. London: Springer; 2003.

42. Jönsson R, Sixt E, Landahl S, Rosenhall U. Prevalence of dizziness and vertigo in an urban elderly population. J Vestib Res. 2004; 14:47-52.

43. Furman JM, Raz Y, Whitney SL. Geriatric vestibulopathy assessment and management. Curr Opin Otolaryngol Head Neck Surg. 2010;18:386-91. https://doi.org/10.1097/MOO.0b013e3283 3 ce5a6.

44. Ribeiro KF, Oliveira BS, Freitas RV, et al. Effectiveness of Otolith repositioning maneuvers and vestibular rehabilitation exercises in elderly people with benign paroxysmal positional vertigo: a systematic review. Braz J Otorhinolaryngol. 2017. https:// doi.org/10.1016/j.bjorl.2017.06.003.

45. Parham K, Kuchel GA. A geriatric perspective on benign paroxysmal positional vertigo. J Am Geriatr Soc. 2016;64:378-85. https://doi.org/10.1111/jgs.13926.

46. Bhattacharyya N, Gubbels SP, Schwartz SR, et al. Clinical practice guideline: benign paroxysmal positional vertigo (Update). Otolaryngol Head Neck Surg. 2017;156:S1-47. https://doi.org/ 10.1177/0194599816689667.

47. Seok JI, Lee HM, Yoo JH, Lee DK. Residual dizziness after successful repositioning treatment in patients with benign paroxysmal positional vertigo. J Clin Neurol. 2008;4:107-10. https:// doi.org/10.3988/jen.2008.4.3.107.

48. Vaduva C, Estéban-Sánchez J, Sanz-Fernández R, Martín-Sanz E. Prevalence and management of post-BPPV residual symptoms. Eur Arch Otorhinolaryngol. 2018;275:1429-37. https:// doi.org/10.1007/s00405-018-4980-x.

49. Jung HJ, Koo J-W, Kim CS, et al. Anxiolytics reduce residual dizziness after successful canalith repositioning maneuvers in benign paroxysmal positional vertigo. Acta Otolaryngol. 2012;132:277-84. https://doi.org/10.3109/00016489.2011. 637179 .

50. Kim M-B, Lee HS, Ban JH. Vestibular suppressants after canalith repositioning in benign paroxysmal positional vertigo. Laryngoscope. 2014;124:2400-3. https://doi.org/10.1002/lary.24741.

51. Guneri EA, Kustutan O. The effects of betahistine in addition to epley maneuver in posterior canal benign paroxysmal positional vertigo. Otolaryngol Neck Surg. 2012;146:104-8. https://doi.org/ 10.1177/0194599811419093.
52. Brandt T, Huppert D, Hecht J, et al. Benign paroxysmal positioning vertigo: a long-term follow-up (6-17 years) of 125 patients. Acta Otolaryngol. 2006;126:160-3. https://doi.org/10.1080/ 00016480500280140.

53. Pérez P, Franco V, Cuesta P, et al. Recurrence of benign paroxysmal positional vertigo. Otol Neurotol. 2012;3:437-43. https:// doi.org/10.1097/MAO.0b013e3182487f78.

54. Yeo S-C, Ahn S-K, Lee HJ, et al. Idiopathic benign paroxysmal positional vertigo in the elderly: a long-term follow-up study. Aging Clin Exp Res. 2018;30:153-9. https://doi.org/10.1007/ s40520-017-0763-2.

55. Li S, Wang Z, Liu Y, et al. Risk factors for the recurrence of benign paroxysmal positional vertigo: a systematic review and meta-analysis. Ear Nose Throat J. 2020. https://doi.org/10.1177/ 0145561320943362.

56. AlGarni MA, Mirza AA, Althobaiti AA, et al. Association of benign paroxysmal positional vertigo with vitamin $\mathrm{D}$ deficiency: a systematic review and meta-analysis. Eur Arch Otorhinolaryngol. 2018;275:2705-11. https://doi.org/10.1007/ s00405-018-5146-6.

57. Neuhauser HK, Lempert T. Vertigo: epidemiologic aspects. Semin Neurol. 2009;29:473-81. https://doi.org/10.1055/s-00291241043.

58. von Brevern M, Radtke A, Lezius F, et al. Epidemiology of benign paroxysmal positional vertigo: a population based study. J Neurol Neurosurg Psychiatry. 2007;78:710-5. https://doi.org/ 10.1136/jnnp.2006.100420.

59. Jeong S-H, Kim J-S, Kim H-J, et al. Prevention of benign paroxysmal positional vertigo with vitamin D supplementation: a randomized trial. Neurology. 2020;95:e1117-25. https://doi.org/ 10.1212/WNL.0000000000010343.

60. Teggi R, Manfrin M, Balzanelli C, et al. Point prevalence of vertigo and dizziness in a sample of 2672 subjects and correlation with headaches. Acta Otorhinolaryngol. 2016. https://doi.org/10. 1439/0392-100X-847.

61. Vibert D, Caversaccio M, Häusler R. Meniere's disease in the elderly. Otolaryngol Clin N Am. 2010;43:1041-6. https://doi. org/10.1016/j.otc.2010.05.009.

62. Hussain K, Murdin L, Schilder AG. Restriction of salt, caffeine and alcohol intake for the treatment of Ménière's disease or syndrome. Cochrane Database Syst Rev. 2018;12:CD012173. https:// doi.org/10.1002/14651858.CD012173.pub2.

63. Casani AP, Navari E, Guidetti G, Lacour M. Good clinical approach: Delphi consensus for the use of betahistine in Menière's disease. Int J Otolaryngol. 2018;2018:5359208. https://doi.org/10.1155/2018/5359208.

64. Adrion C, Fischer CS, Wagner J, et al. Efficacy and safety of betahistine treatment in patients with Meniere's disease: primary results of a long term, multicentre, double blind, randomised, placebo controlled, dose defining trial (BEMED trial). BMJ. 2016;352: h6816. https://doi.org/10.1136/bmj. h6816.

65. James AL, Burton MJ. Betahistine for Menière's disease or syndrome. Cochrane database Syst Rev. 2001;2001:CD001873. https://doi.org/10.1002/14651858.CD001873.

66. Della Pepa C, Guidetti G, Eandi M. Betahistine in the treatment of vertiginous syndromes: a meta-analysis. Acta Otorhinolaryngol Ital. 2006;26:208-15.

67. Lezius F, Adrion C, Mansmann U, et al. High-dosage betahistine dihydrochloride between 288 and $480 \mathrm{mg} /$ day in patients with severe Menière's disease: a case series. Eur Arch Otorhinolaryngol. 2011;268:1237-40. https://doi.org/10.1007/ s00405-011-1647-2.

68. Shen J, Ruckenstein M. Medical treatment of Menière's Disease. In: Menière's disease: evidence and outcomes. San Diego: Plural Publishing; 2010. p. 97-104. 
69. Stern Shavit S, Lalwani AK. Are diuretics useful in the treatment of meniere disease? Laryngoscope. 2019;129:2206-7. https://doi. org/10.1002/lary.28040.

70. Burgess A, Kundu S. Diuretics for Ménière's disease or syndrome. Cochrane Database Syst Rev. 2006. https://doi.org/10. 1002/14651858.CD003599.pub2.

71. Rauch SD. Clinical hints and precipitating factors in patients suffering from Meniere's disease. Otolaryngol Clin N Am. 2010;43:1011-7. https://doi.org/10.1016/j.otc.2010.05.003.

72. Crowson MG, Patki A, Tucci DL. A systematic review of diuretics in the medical management of Ménière's disease. Otolaryngol Head Neck Surg. 2016;154(5):824-34.

73. Basura GJ, Adams ME, Monfared A, et al. Clinical practice guideline: Ménière's disease. Otolaryngol Head Neck Surg. 2020;162:S1-55. https://doi.org/10.1177/0194599820909438.

74. Sepahdari AR, Vorasubin N, Ishiyama G, Ishiyama A. Endolymphatic hydrops reversal following acetazolamide therapy: demonstration with delayed intravenous contrast-enhanced 3D-FLAIR MRI. Am J Neuroradiol. 2016;37:151-4. https://doi.org/10.3174/ ajnr.A4462.

75. Froehlich MH, Lambert PR. The physiologic role of corticosteroids in Menière's disease: an update on glucocorticoid-mediated pathophysiology and corticosteroid inner ear distribution. Otol Neurotol. 2020;41:271-6. https://doi.org/10.1097/MAO.00000 00000002467.

76. Pondugula SR, Raveendran NN, Ergonul Z, et al. Glucocorticoid regulation of genes in the amiloride-sensitive sodium transport pathway by semicircular canal duct epithelium of neonatal rat. Physiol Genom. 2006;24:114-23. https://doi.org/10.1152/physi olgenomics.00006.2005.

77. Nevoux J, Viengchareun S, Lema I, et al. Glucocorticoids stimulate endolymphatic water reabsorption in inner ear through aquaporin 3 regulation. Pflugers Arch. 2015;467:1931-43. https://doi. org/10.1007/s00424-014-1629-5.

78. Otake H, Yamamoto H, Teranishi M, et al. Cochlear blood flow during occlusion and reperfusion of the anterior inferior cerebellar artery - effect of topical application of dexamethasone to the round window. Acta Otolaryngol. 2009;129:127-31. https://doi. org/10.1080/00016480802078119.

79. Morales-Luckie E, Cornejo-Suarez A, Zaragoza-Contreras MA, Gonzalez-Perez O. Oral administration of prednisone to control refractory vertigo in Ménière's disease: a pilot study. Otol Neurotol. 2005;26:1022-6. https://doi.org/10.1097/01.mao.00001 85057.81962.51.

80. Fisher LM, Derebery MJ, Friedman RA. Oral steroid treatment for hearing improvement in Ménière's disease and endolymphatic hydrops. Otol Neurotol. 2012;33:1685-91. https://doi. org/10.1097/MAO.0b013e31826dba83.

81. Patel M, Agarwal K, Arshad Q, et al. Intratympanic methylprednisolone versus gentamicin in patients with unilateral Ménière's disease: a randomised, double-blind, comparative effectiveness trial. Lancet. 2016;388(10061):2753-62. https:// doi.org/10.1016/S0140-6736(16)31461-1.

82. Patel M. Intratympanic corticosteroids in Ménière's disease: a mini-review. J Otol. 2017;3:117-24. https://doi.org/10.1016/j. joto.2017.06.002.

83. Cao Z, Yue F, Huang W, Rajenderkumar D, Zhao F. Different medications for the treatment of Ménière's disease by intratympanic injection: a systematic review and network meta-analysis. Clin Otolaryngol. 2019;44:619-27. https://doi.org/10. 1111/coa.13350.

84. Phillips JS, Westerberg B. Intratympanic steroids for Ménière's disease or syndrome. Cochrane Database Syst Rev. 2011. https://doi.org/10.1002/14651858.CD008514.pub2.

85. Devantier L, Djurhuus BD, Hougaard DD, et al. Intratympanic steroid for Menière's disease: a systematic review. Otol
Neurotol. 2019;40:806-12. https://doi.org/10.1097/MAO. 0000000000002255 .

86. Pullens B, van Benthem PP. Intratympanic gentamicin for Ménière's disease or syndrome. Cochrane Database Syst Rev. 2011. https://doi.org/10.1002/14651858.CD008234.pub2.

87. Naples JG, Henry L, Brant JA, et al. Intratympanic therapies in Ménière disease: evaluation of outcomes and early vertigo control. Laryngoscope. 2019;129:216-21. https://doi.org/10. 1002/lary.27392.

88. Ahmadzai N, Cheng W, Kilty S, et al. Pharmacologic and surgical therapies for patients with Meniere's disease: a systematic review and network meta-analysis. PLoS ONE. 2020;15:1-28. https://doi.org/10.1371/journal.pone.0237523.

89. Casani AP, Piaggi P, Cerchiai N, et al. Intratympanic treatment of intractable unilateral Meniere disease: gentamicin or dexamethasone? A randomized controlled trial. Otolaryngol Neck. 2012;146:430-7. https://doi.org/10.1177/0194599811429432.

90. Jiang M, Zhang Z, Zhao C. What is the efficacy of gentamicin on the incidence of vertigo attacks and hearing in patients with Meniere's disease compared with steroids? A meta-analysis. J Neurol. 2020. https://doi.org/10.1007/s00415-020-10011-5.

91. Yaz F, Ziylan F, Smeeing DPJ, Thomeer HGXM. Intratympanic treatment in Menière's disease, efficacy of aminoglycosides versus corticosteroids in comparison studies: a systematic review. Otol Neurotol. 2020;41:1-10. https://doi.org/10.1097/ MAO.0000000000002451.

92. Espinosa-Sanchez JM, Lopez-Escamez JA. The pharmacological management of vertigo in Meniere disease. Expert Opin Pharmacother. 2020;21:1753-63. https://doi.org/10.1080/ 14656566.2020.1775812.

93. Pagnini P, Vannucchi P, Giannoni B, Pecci R. Epigone migraine vertigo (EMV): a late migraine equivalent. Acta Otorhinolaryngol Ital. 2014;34:62-70.

94. Byun YJ, Levy DA, Nguyen SA, et al. Treatment of vestibular migraine: a systematic review and meta-analysis. Laryngoscope. 2020;131:186-94. https://doi.org/10.1002/lary.28546.

95. Shoair OA, Nyandege AN, Slattum PW. Medication-related dizziness in the older adult. Otolaryngol Clin N Am. 2011;44:455-71. https://doi.org/10.1016/j.otc.2011.01.014.

96. Lepcha A, Amalanathan S, Augustine AM, et al. Flunarizine in the prophylaxis of migrainous vertigo: a randomized controlled trial. Eur Arch Otorhinolaryngol. 2014;271:2931-6. https:// doi.org/10.1007/s00405-013-2786-4.

97. Jhang K-M, Huang J-Y, Nfor ON, et al. Extrapyramidal symptoms after exposure to calcium channel blocker-flunarizine or cinnarizine. Eur J Clin Pharmacol. 2017;73:911-6. https://doi. org/10.1007/s00228-017-2247-x.

98. Centonze V, Magrone D, Vino M, et al. Flunarizine in migraine prophylaxis: efficacy and tolerability of $5 \mathrm{mg}$ and $10 \mathrm{mg}$ dose levels. Cephalalgia. 1990;10:17-24. https://doi.org/10.1046/j. 1468-2982.1990.1001017.x.

99. Benvenuti F, Baroni A, Bandinelli S, et al. Flunarizine-induced parkinsonism in the elderly. J Clin Pharmacol. 1988;28:600-8. https://doi.org/10.1002/j.1552-4604.1988.tb03183.x.

100. Ziegler VE, Biggs JT. Electrocardiographic findings in patients undergoing amitriptyline treatment. Dis Nerv Syst. 1977;38:697-9.

101. Mulleners WM, Chronicle EP. Anticonvulsants in migraine prophylaxis: a Cochrane review. Cephalalgia. 2008;28:585-97. https://doi.org/10.1111/j.1468-2982.2008.01571.x.

102. Liu F, Ma T, Che X, et al. The efficacy of venlafaxine, flunarizine, and valproic acid in the prophylaxis of vestibular migraine. Front Neurol. 2017;8:524. https://doi.org/10.3389/fneur.2017. 00524.

103. Ophoff RA, Terwindt GM, Vergouwe MN, et al. Familial hemiplegic migraine and episodic ataxia type- 2 are caused 
by mutations in the $\mathrm{Ca}^{2+}$ channel gene CACNL1A4. Cell. 1996;87:543-52. https://doi.org/10.1016/s0092-8674(00) 81373-2.

104. De Simone R, Marano E, Di Stasio E, et al. Acetazolamide efficacy and tolerability in migraine with aura: a pilot study. Headache. 2005;45:385-6. https://doi.org/10.1111/j.1526-4610.2005. 05077_3.x.

105. Çelebisoy N, Gökçay F, Karahan C, et al. Acetazolamide in vestibular migraine prophylaxis: a retrospective study. Eur Arch Otorhinolaryngol. 2016;273:2947-51. https://doi.org/10.1007/ s00405-015-3874-4.

106. Grazzi L, Toppo C, Damico D, et al. Non-pharmacological approaches to headaches: non-invasive neuromodulation, nutraceuticals, and behavioral approaches. Int J Environ Res Public Health. 2021;18:1503. https://doi.org/10.3390/ijerph18041503.

107. Beh SC, Friedman DI. Acute vestibular migraine treatment with noninvasive vagus nerve stimulation. Neurology. 2019;93:e1715-1719.

108. Henssen DJHA, Derks B, van Doorn M, et al. Vagus nerve stimulation for primary headache disorders: an anatomical review to explain a clinical phenomenon. Cephalalgia. 2019;39:1180-94.

109. Lauver DA, Lucchesi BR. Sulodexide: a renewed interest in this glycosaminoglycan. Cardiovasc Drug Rev. 2006;24:214-26. https://doi.org/10.1111/j.1527-3466.2006.00214.x.

110. Sohn SH, Kim TS, Kim JW, Yoo SM, Jo WM. Anti-thrombotic and anti-inflammatory activity of sulodexide compared to aspirin in the rat model. Clin Hemorheol Microcirc. 2020. https://doi. org/10.3233/ch-201043.

111. Adiguzel C, Iqbal O, Hoppensteadt D, et al. Comparative anticoagulant and platelet modulatory effects of enoxaparin and sulodexide. Clin Appl Thromb. 2009;15:501-11. https://doi.org/10. 1177/1076029609338711.

112. Neri G, Marcelli V, Califano L. Assessment of the effect of mesoglycan in the treatment of audiovestibular disorders of vascular origin. Int J Immunopathol Pharmacol. 2018;32:2058738418773833. https://doi.org/10.1177/20587 38418773833 .

113. Canova D, Roatta S, Micieli G, Bosone D. Cerebral oxygenation and haemodynamic effects induced by nimodipine in healthy subjects. Funct Neurol. 2012;27:169-76.

114. Pantoni L, del Ser T, Soglian AG, et al. Efficacy and safety of nimodipine in subcortical vascular dementia: a randomized placebo-controlled trial. Stroke. 2005;36:619-24. https://doi.org/10. 1161/01.STR.0000155686.73908.3e.

115. Eicher H, Hilgert D, Zeeh J, et al. Pharmacokinetics of nimodipine in multimorbid elderly patients with chronic brain failure. Arch Gerontol Geriatr. 1992;14:309-19. https://doi.org/10.1016/ 0167-4943(92)90030-8.
116. Cerchiai N, Mancuso M, Navari E, Giannini N, Casani AP. Aging with cerebral small vessel disease and dizziness: the importance of undiagnosed peripheral vestibular disorders. Front Neurol. 2017;8:241. https://doi.org/10.3389/fneur.2017.00241.

117. Baezner H, Blahak C, Poggesi A, et al. Association of gait and balance disorders with age-related white matter changes: the LADIS study. Neurology. 2008;70:935-42. https://doi.org/10. 1212/01.wnl.0000305959.46197.e6.

118. Wharton SB, Simpson JE, Brayne C, Ince PG. Age-associated white matter lesions: the MRC cognitive function and ageing study. Brain Pathol. 2015;25:35-43. https://doi.org/10.1111/bpa. 12219.

119. Ahmad H, Cerchiai N, Mancuso M, et al. Are white matter abnormalities associated with "unexplained dizziness"? J Neurol Sci. 2015;358:428-31. https://doi.org/10.1016/j.jns.2015.09.006.

120. Ulivi L, Maccarrone M, Giannini N, et al. Oxidative stress in cerebral small vessel disease dizziness patients, basally and after polyphenol compound supplementation. Curr Mol Med. 2018;18(3):160-5. https://doi.org/10.2174/156652401866618 0720165055.

121. Bath PM, Wardlaw JM. Pharmacological treatment and prevention of cerebral small vessel disease: a review of potential interventions. Int J Stroke. 2015;10:469-78. https://doi.org/10.1111/ ijs.12466.

122. Gamba P, Pavia M. White matter lesions and vascular vertigo: clinical correlation and findings on cranial magnetic resonance imaging. Eur Rev Med Pharmacol Sci. 2016;04:2786-91.

123. Staab JP, Ruckenstein MJ, Solomon D, Shepard NT. Serotonin reuptake inhibitors for dizziness with psychiatric symptoms. Arch Otolaryngol Head Neck Surg. 2002;128:554-60. https:// doi.org/10.1001/archotol.128.5.554.

124. Whitney SL, Alghwiri AA, Alghadir A. An overview of vestibular rehabilitation. Handb Clin Neurol. 2016;137:187-205. https:// doi.org/10.1016/B978-0-444-63437-5.00013-3.

125. Staab JP, Ruckenstein MJ, Amsterdam JD. A prospective trial of sertraline for chronic subjective dizziness. Laryngoscope. 2004;114:1637-41. https://doi.org/10.1097/00005537-20040 9000-00025.

126. Ungvari Z, Tarantini S, Yabluchanskiy A, Csiszar A. Potential adverse cardiovascular effects of treatment with fluoxetine and other selective serotonin reuptake inhibitors (SSRIs) in patients with geriatric depression: implications for atherogenesis and cerebromicrovascular dysregulation. Front Genet. 2019;10:898. https://doi.org/10.3389/fgene.2019.00898.

127. Herdman S, Clendaniel R. Vestibular rehabilitation. 4th ed. F A Davis Co; 2014. 